
\title{
R Reserach S Suare \\ Identification of a Saltol-independent Salinity Tolerance Polymorphism in Rice Mekong Delta Landraces and Characterization of a Promising Line, Doc Phung
}

Nguyen Thanh Tam

Can Tho University

Maria Stefanie Dwiyanti

Hokkaido University

Shuntaro Sakaguchi

Hokkaido University

Yohei Koide

Hokkaido University

Le Viet Dung

Can Tho University

Toshihiro Watanabe

Hokkaido University

Yuji Kishima ( $\square$ kishima@abs.agr.hokudai.ac.jp)

Hokkaido University

\section{Research Article}

Keywords: Mekong Delta, Salinity tolerance, Rice, Doc Phung, GWAS (genome-wide association study), SES (standard evaluation system), Mineral concentrations, OsPLGG1

Posted Date: December 13th, 2021

DOI: https://doi.org/10.21203/rs.3.rs-1129525/v1

License: (c) (i) This work is licensed under a Creative Commons Attribution 4.0 International License.

Read Full License 


\section{Abstract}

The Mekong Delta River in Vietnam is facing salinity intrusion caused by climate change and sea-level rise that is severely affecting rice cultivation. Here, we evaluated salinity responses of 97 rice accessions (79 landraces and 18 improved accessions) from the Mekong Delta population by adding $100 \mathrm{mM} \mathrm{NaCl}$ to the nutrient solution for up to 20 days. We observed a wide distribution in salinity tolerance/sensitivity, with two major peaks across the 97 accessions when using the standard evaluation system (SES) developed by the International Rice Research Institute. SES scores revealed strong negative correlations (ranging from -0.68 to -0.83 ) with other phenotypic indices, such as shoot elongation length, root elongation length, shoot dry weight, and root dry weight. Mineral concentrations of $\mathrm{Na}^{+}$in roots, stems, and leaves and $\mathrm{Ca}^{2+}$ in roots and stems were positively correlated with SES scores, suggesting that tolerant accessions lower their cation exchange capacity (CEC) in the root cell wall. The salinity tolerance of Mekong Delta accessions was independent from the previously described salinity tolerance-related locus Saltol, which encodes an HKT1-type transporter in the salinity-tolerant cultivars Nona Bokra and Pokkali. Indeed, genome-wide association studies (GWASs) using SES scores and shoot dry weight ratios of the 79 accessions as traits identified a single common peak located on chromosome 1 . This SNP did not form a linkage group with other nearby SNPs and mapped to the $3^{\prime}$ untranslated region of gene LOC_Os01g32830, over 6.5 Mb away from the Salto/ locus. LOC_Os01g32830 encodes chloroplast glycolate/glycerate translocator 1 (OsPLGG1), which is responsible for photorespiration and growth. SES and shoot dry weight ratios differed significantly between the two possible haplotypes at the causal SNP. Through these analyses, we characterize Doc Phung, one of the most salt-tolerant varieties in the Mekong Delta population and a promising new genetic resource.

\section{Background}

Rice (Oryza sativa L.) is a main staple food source for about $90 \%$ of Asian people and is grown in areas with easy access to water. One of greatest threats to rice production is salinity stress (Maas and Grattan 1999). In coastal and/or acid and semi-arid areas, the effect of salt conditions is a major issue for rice production. In particular, about 500,000 ha around coastal areas in the Mekong Delta/River are predicted to become affected by salinity intrusion caused by climate change and the rise of sea levels by 2050 , with this number increasing 10-fold when considering the worst case scenario of combined climate change, sea-level rise, and low river flows (Kontgis et al. 2019). Salt intrusion from the sea can impose salt stress during the dry season, when saltwater seeps into the ground freshwater (Nhung et al. 2019). The use of salinity-tolerant varieties is seen as a more efficient and effective mitigating measure than farming practices or salinity management facilities such as dikes, pumping stations, and sluices (Akbar et al. 1972).

Rice is generally sensitive to high-salt conditions, especially at the seedling stage (Batayeva et al. 2018; De Leon et al. 2016; Kumari et al. 2009; Lutts et al. 1995; Mohammadi-Nejad et al. 2010; Puram et al. 2017; Tian et al. 2011). Much effort has been made to screen and select salinity-tolerant rice varieties (De Leon et al. 2017; Ganie et al. 2019; Hariadi et al. 2015; Lee et al. 2003), such as the high-salt-tolerant 
'Nona Bokra' and 'Pokkali', which have greatly contributed to salt-tolerant rice breeding (Ren et al. 2005; Thomson et al. 2010). These indica strains are landraces from the Indian and Sri Lanka coastal regions, respectively. Their salt tolerance may have been achieved by adapting to high-salt soils (Emon et al. 2015; Gregorio and Senadhira 1993). The Saltol locus defined a strong-effect quantitative trait locus (QTL) associated with this salt tolerance and was mapped to chromosome 1 (Bonilla et al. 2002; Xie et al. 2000). The Salto/ locus was later shown to encode a HIGH-AFFINITY K ${ }^{+}$TRANSPORTER1 (HKT1)-type sodium ( $\mathrm{Na}^{+}$) transporter (Ren et al. 2005). However, the biological response to salt is extremely complex, and not all salt tolerance can be explained by the Saltollocus. In fact, other salt-tolerant landrace varieties from Bangladesh and Saudi Arabia have a Saltol haplotype distinct from that of Nona Bokra or Pokkali (Bimpong et al. 2014; Rahman et al. 2017; Rahman et al. 2019). Several QTL analyses have revealed various mechanisms involved in rice salt tolerance (Singh et al. 2021).

The mechanisms related to salt tolerance of rice can broadly be divided into three categories (Marschner 2012): $\mathrm{Na}^{+}$exclusion, osmotic stress regulation, and tissue tolerance to $\mathrm{Na}^{+}$accumulation (Munns and Tester 2008). $\mathrm{Na}^{+}$absorbed by the roots is transported from the xylem to the shoots. $\mathrm{Na}^{+}$accumulation in the shoots is negatively correlated with salt tolerance, as excess $\mathrm{Na}^{+}$levels in cells have a detrimental effect on plant growth (Faiyue et al. 2012; Krishnamurthy et al. 2011; Platten et al. 2013). In the context of $\mathrm{Na}^{+}$exclusion, the salt-resistant Salto/haplotype, such as that harbored by Nona Bokra and Pokkali, rely on the activity of OsHKT1;5, a Na+ ion transporter that can avoid the accumulation of $\mathrm{Na}^{+}$in shoots (Platten et al. 2013; Ren et al. 2005). Osmotic regulation modulates stomatal conductance before too much $\mathrm{Na}^{+}$accumulates in shoots by reducing water evaporation and, thus, the flow of water from roots to shoots, resulting in salt resistance (Rios et al. 2017; Termaat et al. 1985). Tissue tolerance refers to the mechanism that prevents toxic $\mathrm{Na}^{+}$levels from accumulating in cells (Davenport et al. 2005). Several known mechanisms prevent $\mathrm{Na}^{+}$from being released into the cytoplasm by sequestration of $\mathrm{Na}^{+}$ into vacuoles or by releasing $\mathrm{Na}^{+}$into the soil (Anil et al. 2007; Bassil et al. 2012; Kader et al. 2007). Under saline conditions, concentrations for the cation $\mathrm{Na}^{+}$and the anion $\mathrm{Cl}^{-}$increase in all plant organs, while the absorption of $\mathrm{K}^{+}, \mathrm{Ca}^{2+}, \mathrm{Mg}^{2+}$, and $\mathrm{Mn}^{2+}$ decrease (Grattan and Grieve 1999). Limiting the uptake of these essential ions negatively affects plant growth (Kumar et al. 2015).

In this study, we investigated the salt tolerance and physiological characteristics of a diverse panel of landrace rice accessions cultivated in the Mekong Delta region (Tam et al. 2019). We focused on the rice landrace variety 'Doc Phung', known to be particularly resistant to salt in the Mekong Delta (Ho et al. 2018; Le 1999; Tin et al. 2021). Based on the genomic structure of these Mekong Delta populations and GWAS results, we explored and resolved the relationship between the degree of salt tolerance, physiological characteristics, and genomic structure. Analysis of whole-genome sequences provided evidence that Doc Phung carries a Saltol allele different from that of Nona Bokra or Pokkali and that the causative region of salt tolerance might have enabled the adaptation to the coastal areas of the Mekong Delta. 


\section{Materials And Methods}

\section{Plant Materials}

Ninety-seven rice accessions consisting of 79 landraces and 18 improved accessions were selected from the Genebank of Mekong Delta Development Research Institute (MDI), Can Tho University, Vietnam (Supplementary Table 1) (Tam et al. 2019). 'Nipponbare' and 'Pokkali' were added as sensitive and tolerant cultivar controls, respectively, for salinity stress. However, as Pokkali supplied by the International Rice Research Institute (IRRI) did not show the expected high tolerance in our assays, we stopped using this material.

\section{Screening for Salinity Tolerance}

Seeds were treated with disinfectant (20\% [v/v] solution of Tekurido C, Kumiai Chemical Industry Co., LTD) for $15 \mathrm{~min}$ for surface sterilization. Seeds were then washed with tap water three times and with distilled water two times. Surface-sterilized seeds were placed into petri dishes and germinated in dark conditions at $25^{\circ} \mathrm{C}$. Three days after germination, seedlings were transplanted to net sheets floating on distilled water in a $40-\mathrm{L}$ container at $20-25^{\circ} \mathrm{C}$ in the greenhouse. Four days after transfer (DAT), water was replaced with standard nutrient solution: $1.12 \mathrm{mM} \mathrm{NH}_{4} \mathrm{NO}_{3}, 0.32 \mathrm{mM} \mathrm{NaH}_{2} \mathrm{PO}_{4}, 0.19 \mathrm{mM} \mathrm{K}_{2} \mathrm{SO}_{4}$, $0.38 \mathrm{mM} \mathrm{KCl}, 1.25 \mathrm{mM} \mathrm{CaCl}_{2}, 0.82 \mathrm{mM} \mathrm{MgSO}_{4}, 35.8 \mu \mathrm{M} \mathrm{Fe}$-EDTA, $9.1 \mu \mathrm{M} \mathrm{Mn}_{2} \mathrm{SO}_{4}, 3.06 \mu \mathrm{M} \mathrm{ZnSO}_{4}, 0.16$ $\mu \mathrm{M} \mathrm{CuSO}_{4}, 46.2 \mu \mathrm{M} \mathrm{H}_{3} \mathrm{BO}_{3}$, and $0.052 \mu \mathrm{M}\left(\mathrm{NH}_{4}\right)_{6} \mathrm{Mo}_{7} \mathrm{O}_{24}$. The nutrient solution was replaced every 3 days, and the $\mathrm{pH}$ was adjusted to 5.0 every day with $1 \mathrm{M} \mathrm{NaOH}$ or $0.5 \mathrm{M} \mathrm{HCl}$, as needed. At $15 \mathrm{DAT}$, the salt stress treatment was started by adding $100 \mathrm{mM} \mathrm{NaCl}$ to the nutrient solution. Immediately before treatment, the shoot and root lengths of all samples were measured. Five days into treatment (DIT), shoot and root elongation lengths were determined, as well as visible phenotypes in response to salinity stress, using the modified standard evaluation system (SES) score developed by IRRI (IRRI 2013) to assess salinity tolerance in each accession (Supplementary Table 2). At 20 DIT, all phenotypes were scored again with the SES, and shoot and root elongation lengths were measured, after which the samples were collected. All plants were washed in tap water (twice) and then in distilled water twice to remove salts on the plant surface. Plants were separated into two parts (shoot and root), dried at $70^{\circ} \mathrm{C}$ for $80 \mathrm{~h}$, and weighed as shoot dry weight and root dry weight. The shoot dry weight of each accession was used for the genome-wide association study (GWAS).

\section{Mineral Analysis}

To perform mineral analysis, 20 accessions with varying SES scores were selected from the initial $97 \mathrm{MDI}$ accessions (Supplementary Table 1). Plants grown in standard nutrient solution or with $100 \mathrm{mM} \mathrm{NaCl}$ for 20 days (20 DIT) were dried and divided into four parts: roots, upper stems (hereafter stems), lower stems, and leaves; lower stem samples were not analyzed due to contamination of the culture solution. Samples were ground to powder (30-40 mg) and digested with $2 \mathrm{~mL}$ of $60 \%(\mathrm{w} / \mathrm{v}) \mathrm{HNO}_{3}$ in a tube at $107.5^{\circ} \mathrm{C}$ in a DigiPREP apparatus (SCP Science, Quebec, Canada) for $4 \mathrm{~h} ; 0.5 \mathrm{~mL}$ of $30 \%$ hydrogen peroxide was added, and the samples were heated to $107.5^{\circ} \mathrm{C}$. The tubes were allowed to cool to room temperature, 
and their volumes were adjusted to $10 \mathrm{~mL}$ with $2 \%(\mathrm{w} / \mathrm{v}) \mathrm{HNO}_{3}$. The mineral ion composition for $\mathrm{Na}^{+}, \mathrm{K}^{+}$, $\mathrm{Ca}^{2+}$, and $\mathrm{Mg}^{2+}$ was determined by inductively coupled mass spectrometry (ICP-MS) (ELAN, DRC-e, Perkin-Elmer, Waltham, MA, USA) using a blank sample to account for chemical contaminations.

\section{Mineral Data Analysis}

The average value of three biological replications for each accession was calculated. The relative elongation rates of shoots and roots were calculated as follows:

$$
R=\frac{A}{B}
$$

where $\mathrm{R}$ is relative elongation, $\mathrm{A}$ is (shoot length/root length at $20 \mathrm{DIT}$ - shoot length/root length at 0 DIT) of $\mathrm{NaCl}$ treatment, and $\mathrm{B}$ is (shoot length/root length at $20 \mathrm{DIT}$ - shoot length/root length at 0 DIT) of control treatment.

\section{Genome-Wide Association Study (GWAS)}

A dataset of 578,704 single nucleotide polymorphisms (SNPs) distributed across the 12 rice chromosomes in the 97 accessions previously obtained by restriction site-associated DNA sequencing (RAD-seq) (Tam et al. 2019) was filtered for a minimum call rate of $60 \%$, a heterozygous rate below $20 \%$, and a minor allele frequency below $2 \%$, resulting in 37,643 SNPs. Imputation of missing genotypes was performed using Beagle v5.0 (Browning et al. 2018). The set of 37,643 SNPs was also filtered for 79 landraces based on the same criteria above, yielding 29,881 SNPs. GWAS was performed using a general linear model (GLM) in TASSEL 5.2.50 (Bradbury et al. 2007). The population structure component was determined using principal component analysis (PCA) implemented in TASSEL. The significant threshold was set to $p<0.0001$ ( $-\log _{10} p$-value $>4.0$ ). Subsequently, SNPs with a $q$-value (false discovery rate [FDR]-adjusted $p$-value) lower than 0.05 were selected as significant markers with $\mathrm{R}$ software (Storey et al. 2004).

\section{Whole-Genome Resequencing}

The whole-genome resequencing of the $20 \mathrm{MDI}$ accessions selected from the $97 \mathrm{MDI}$ accessions (Supplementary Table 1) was done using the Illumina Hiseq 150-bp Paired End platform, and $4.5 \mathrm{~Gb}$ data were obtained for each accession. After filtering and trimming low-quality reads, read mapping to reference genome Nipponbare and variant calling were performed using BWA-mem (Li and Durbin 2009) and the GATK pipeline (DePristo et al. 2011).

\section{Haplotype Analysis}

Candidate genes (near peak SNPs) were searched in QTL and gene databases in the rice SNP seek database (Mansueto et al. 2017). Linkage disequilibrium (LD) analysis was performed using SNPs 
located within 200-kb windows upstream and downstream of the SNP peaks based on the Haploview method according to Barrett et al. (2005).

\section{Results}

\section{Evaluation of 97 Rice Accessions from the Mekong Delta Region}

We evaluated the salinity tolerance of 97 accessions from the Mekong Delta region to select highly tolerant accessions. In preliminary tests with 50 and $100 \mathrm{mM}$ of $\mathrm{NaCl}$ solution, $100 \mathrm{mM} \mathrm{NaCl}$ clearly revealed differences across accessions (Supplementary Table 3). We scored the salinity responses according to SES developed by IRRI (Supplementary Table 2) (IRRI 2013). Distributions of SES scores for salt tolerance changed among different accessions at 5, 10, 15, and 20 days into salt treatment (DIT). As the length of salt exposure increased, so did the SES scores, with two peaks emerging with SES scores between 3-4 and 8-9 (Figure 1). At 5 DIT, about $66 \%$ of all accessions presented a SES score below 3 (indicating high tolerance), while the remaining 34\% of accessions had SES scores between 3 and 5 (tolerance). By contrast, only five accessions retained an SES score below 3 at 20 DIT, 47 accessions had an SES score of 3-5 (moderate tolerance), and 28 accessions had an SES score of 8-9 (sensitive) (Figure 1). We concluded that 20 DIT is the most suitable screening condition to evaluate salinity responses of the accessions.

\section{Correlations between Phenotypic Traits and SES Scores from 97 Accessions}

To explore possible correlations between SES scores and phenotypic traits, we examined shoot and root elongation lengths, as well as shoot and root dry weights after exposure to $100 \mathrm{mM} \mathrm{NaCl}$ for 20 days (Supplementary Table 4). Accordingly, we calculated the ratios of these four traits between NaCl-treated and control samples for all accessions. All ratios at 20 DIT were strongly and negatively correlated with SES scores (Figure 2). Pearson's correlation coefficients also supported these strong negative correlations, with values ranging from -0.68 to -0.83 (Figure $2 A-D$ ). The shoot dry weight ratio showed the strongest correlation with SES score, with a Pearson's correlation coefficient of -0.83 (Figure $2 \mathrm{C}$ ), while the shoot length ratio was least affected with a Pearson's correlation coefficient of -0.68 (Figure $2 A)$. When plotting the sum of the ratios for the four above traits as a function of SES score, we noticed that the top eight summed phenotypic values match eight of the nine lowest SES scores (Supplementary Table 4), indicating that SES scores are an acceptable index reflecting salinity tolerance. Among the examined accessions, MDI-21 showed the best performance in terms of salinity tolerance, as evidenced by a low SES score and high phenotypic ratios (Supplementary Table 4). Notably, MDI-21 was the variety Doc Phung, known to be highly salt tolerant (Ho et al. 2018).

\section{Mineral Concentrations in Saline Conditions}

We selected 20 accessions with varying levels of salinity response from the initial collection of 97 MDI landraces to examine their mineral concentrations. These accessions comprised eight salinity-tolerant accessions (SES < 4) and 12 sensitive accessions (SES > 4) (Supplementary Table 5). We determined the 
concentrations of four elements $\left(\mathrm{Na}^{+}, \mathrm{K}^{+}, \mathrm{Ca}^{2+}\right.$, and $\left.\mathrm{Mg}^{2+}\right)$ in roots, stems, and leaves (Figure 3 , Supplementary Table 5). Under high-salinity conditions (100 mM NaCl), $\mathrm{Na}^{+}$concentrations were significantly lower at $p$-value $<0.05$ in the tolerant accessions compared to sensitive accessions in all three organs, as were $\mathrm{Ca}^{2+}$ concentrations in roots and stems (Figure 3A). By contrast, $\mathrm{Mg}^{2+}$ concentrations were significantly higher in leaves of tolerant accessions than in those of sensitive accessions (Figure 3A). We observed no differences between tolerant or sensitive accessions for $\mathrm{K}^{+}$in leaves, $\mathrm{Ca}^{2+}$ in leaves, and $\mathrm{Mg}^{2+}$ in stems (Figure $3 \mathrm{~A}$ ). Under normal growth conditions, the concentrations for $\mathrm{Na}^{+}, \mathrm{K}^{+}, \mathrm{Ca}^{2+}$, and $\mathrm{Mg}^{2+}$ in roots, stems, and leaves were not different between saltsensitive and -tolerant accessions (Figure 3B). We tested for correlations between mineral concentrations and tolerance/sensitivity, which revealed that $\mathrm{Na}^{+}$and $\mathrm{Ca}^{2+}$ concentrations are positively correlated with SES scores in the 20 selected accessions, in particular $\mathrm{Na}^{+}$concentrations in leaves $(r=0.66)$ and $\mathrm{Ca}$ concentrations in roots $(r=0.765)$ and stems $(r=0.64)$ (Supplementary Figure 1$)$. We obtained the lowest mineral concentrations in MDI-21 (Doc Phung), which also had the lowest SES at 20 DIT (Supplementary Table 5). We observed no clear correlations between $\mathrm{K}^{+}$concentrations and SES scores among the 20 accessions.

\section{Comparison of the OsHKT1;5 Gene among $20 \mathrm{MDI}$ Accessions and Nona Bokra/Pokkali}

The OsHKT1;5 gene underlies the Saltol locus, whose alleles from the Nona Bokra and Pokkali varieties confer tolerance to high salinity. To assess whether Salto/ contributes to salinity sensitivity/tolerance in the MDI accessions, we compared the OsHKT1,5 genomic sequences from the $20 \mathrm{MDI}$ accessions to the Nona Bokra/Pokkali allele. To this end, we extracted the OsHKT1;5 sequences and inferred the amino acid (aa) sequences from $20 \mathrm{MDI}$ rice accessions representing $97 \mathrm{MDI}$ rice accessions chosen for wholegenome resequencing. In Nona Bokra/Pokkali, the OsHKT1;5 open reading frame was 1,662 bp in length and encoded a protein of 554 aa (Figure 4A). Six amino acid residues showed nonsynonymous polymorphisms for OsHKT1;5 among the 20 MDI accessions, Nipponbare and Nano Bokra/Pokkali (Figure 4B), defining six haplotypes. The accession MDI-44 shared the same OsHKT1;5 haplotype with Nano Bokra/Pokkali, although it was not a highly tolerant accession, with an SES score of 4 (Figure 4B). Haplotype 1 contained 10 accessions, including the highly tolerant MDI-21, and showed a broad range of SES scores (Figure 4B). The four accessions belonging to haplotype 2 displayed varied SES scores, as with haplotype 1 (Figure 4B). We concluded from these results that the genotype at OsHKT1;5 is not strongly correlated with salinity tolerance of the $20 \mathrm{MDI}$ accessions tested here. These results thus suggested that the salinity tolerance in the MDI accessions is genetically distinct from the Saltol locus harbored by Nano Bokra/Pokkali.

\section{Manhattan plots for the SES Score of MDI Rice Accessions}

The above results showed that salinity tolerance in the MDI accessions may be regulated by loci different from the Saltol locus encoding the OsHKT1;5 transporter. To look for additional loci related to salinity tolerance, we performed GWASs using 37,643 imputed SNPs obtained from RAD-seq data from the 97 
MDI accessions (Tam et al. 2019). We produced Manhattan plots using 29,881 SNPs from the 79 MDI landraces (97 MDI minus 18 improved varieties) using their SES scores at 20 DIT as the trait. We observed significant associations with three genomic regions for SES scores on chromosomes 1, 4, and 5. These three regions consisted of five SNP markers: one on chromosome 1, two on chromosome 4, and two on chromosome 5, with a significance threshold - $\log (p$-value) $>4.0$ (Figure $5 \mathrm{~A})$. When adjusting the threshold to account for a false discovery rate $(q$-value $)<0.1$, only one SNP on chromosome 1 (S01_18015212) remained significant (Supplementary Table 6A).

We detected the same SNP peak when using shoot dry weight as the trait, which was the most highly correlated out of the four phenotypes measured, based on Pearson's correlation coefficients, with SES scores (Figure 5B). The GWAS returned 23 significant SNPs mapping to nine chromosomes for shoot dry weight with the threshold - Log ( $p$-value) $\geq 4.0$, on chromosomes 1, 2, 3, 5, 7, 8, 10, 11, and 12 (Figure $5 B$ ). We retained eight SNPs on five chromosomes with a $q$-value $\leq 0.05$ (Figure 5B). Importantly, SNP S01_18015212, which was associated with SES score, was the most significant for shoot dry weight (Supplementary Table 5B).

\section{Linkage disequilibrium (LD) and Haplotypes around the SNP Peak Region}

We analyzed the SNPs over a 200-kb window (100 kb upstream and $100 \mathrm{~kb}$ downstream of the peak SNP). After filtering, we retained 19 SNPs for LD analysis based on the Haploview method (Figure 5C, D). Surprisingly, the peak SNP (S01_18015212) did not group with other SNPs within the neighboring 200-kb window (Figure 5C), indicating that no other nearby SNP interacts with SNP (S01_18015212). Furthermore, we examined SNP (S01_18015212) using whole-genome resequencing data from the 20 accessions, resulting in 657 SNPs within the same 200-kb window. Again, the peak SNP S01_18015212 was the only site showing a peak in Manhattan plots and showed no LD with other linked SNPs (Figure 5D).

SNP S01_18015212 mapped to the 3' untranslated region (UTR) of LOC_Os01g32830 on chromosome 1, about 6.5 Mb away from the Saltol locus (Figure 6A), clearly indicating that the Saltol allele does not play a role in salt tolerance in these accessions. LOC_Os01g32830 encodes a predicted chloroplast-localized transmembrane protein: chloroplast glycolate/glycerate translocator 1 (OsPLGG1). (Shim et al. 2019). PLGG1 transports glycolate/glycerate produced in chloroplasts to peroxisomes during photorespiration (Pick et al. 2013).

We identified 3 possible haplotypes among 79 rice accessions at SNP S01_18015212: 61 accessions harboring the $\mathrm{C}$ allele (Hap 1), 10 carrying the A allele (Hap 2), and 8 heterozygous accessions (not evaluated here for haplotype comparison) (Figure 6B). The average SES score $(4.2 \pm 0.48)$ of accessions with the $A$ allele was significantly lower than in accessions with the $C$ allele $(7.0 \pm 0.26)$ (Figure 6B, C). The shoot dry weight ratio showed the opposite pattern relative to SES scores, with Hap1 associated with a lower ratio than Hap 2 (Figure 6B, D). We concluded that Hap 2 is a salinity-tolerant haplotype, while Hap 1 was sensitive to salinity. The variety Doc Phung belonged to Hap 2. 


\section{Discussion}

\section{Geographical Association with Salt Stress Responses in MDI Strains}

The evaluation of SES scores for $97 \mathrm{MDI}$ accessions exposed to $100 \mathrm{mM} \mathrm{NaCl}$ for 20 days revealed two major peaks for salt tolerance: one peak from a group with high-salt tolerance (SES score between 3 and 5) and another peak from a group with low-salt tolerance (SES scores between 8 and 9) (Figure 1). We observed regional differences between the coastal and inland areas of the Mekong Delta for the distribution of high- and low-salt tolerance groups, especially for high-salt-tolerant accessions, which were mostly derived from the coastal Ca Mau region (Figure 7, Supplementary Table 1). It is possible that adaptive selection for salt tolerance acted on these accessions originating from the Ca Mau coastal region, in an analogous manner to the salt-tolerant varieties Nona Bokra and Pokkali, whose indigenous varieties originated from Bangladesh and coastal India, respectively (Emon et al. 2015; Gregorio and Senadhira 1993). On the other hand, Doc Phung does not originate from the Ca Mau region but from the Ben Tre region, and the salt-tolerant allele of the Hap2 type is widely distributed in the coastal areas of the Mekong Delta (Figure 7). In agreement, inland strains tended to be less salt tolerant, may have grown with little exposure to salt stress, and were likely to possess genomic structures similar to accessions from Cambodia and Laos (Tam et al. 2019). The three genomic regions identified by GWASs clearly illustrated the difference in genome structure between local coastal and inland accessions of the Mekong Delta (Figure 7). The observed difference in salt tolerance, along with the differences in genomic structures, suggests that genetic exchange between the native lineages has been limited.

\section{Genetic Association with Diversity of Salt Stress Responses in MDI Strains}

We used the SES score for salt tolerance developed by IRRI to evaluate our accessions at the seedling stage (IRRI 2013). SES scores for each accession were strongly and negatively correlated with their salt response phenotypes and the ratios for shoot length, root length, shoot dry weight, and root dry weight, with Pearson's correlation coefficients no higher than -0.67 (Figure 2). These correlations demonstrated that the SES score is a good indicator of salt tolerance. Shoot dry weight ratios showed the strongest correlation with SES scores (Figure 2). Using the shoot dry weight ratio and SES scores for GWAS, we identified a significant peak at a single SNP on chromosome 1 for both traits (Figure 5A, B). We identified the same single SNP, S01_18015212, in a subsequent GWAS based on the resequencing data of 20 accessions with different SES scores (Figure 5C, D). Although several salt-response-related genes, including the Saltol locus (Ren et al. 2005; Thomson et al. 2010), are located on chromosome 1, the gene to which the peak SNP mapped is a previously uncharacterized gene, with the SNP located in the 3' UTR (Figure 6A).

\section{Possible Functions of the SNP in the 3' UTR of LOC_Os01g32830 (OsPLGG1)}

The IRRI Rice SNP-Seek Database (Mansueto et al. 2017) and RAP DB (Sakai et al. 2013) revealed that SNP S01_18015212 maps to LOC_Os01g32830 (Os01t0511600-01). Os01t0511600-01 encodes OsPLGG1 responsible for the transport of glycolate/glycerate from chloroplasts to peroxisomes (Shim et 
al. 2019). Mutants in OSPLGG1 exhibit lower photosynthetic efficiency, starch accumulation, plant height, and crop productivity (Shim et al. 2019). Salt stress is known to result in excess reactive oxygen species (ROS), which interferes with normal photosynthesis and negatively affect plant growth (Pawlowicz et al. 2018; Yang et al. 2020). We hypothesize that variation in OsPLGG1 activity in transporting glycolate/glycerate from chloroplasts to peroxisomes may contribute to the accumulation of ROS in response to salt stress, which affects photosynthetic reactions and plant growth.

SNP S01_18015212 is located in the 3' UTR of the gene, which typically participates in the regulation of mRNA stability, localization, or translation; this SNP may thus affect protein abundance (Sun et al. 2017). In addition, 3' UTRs are known to control gene expression in plants, especially when exposed to environmental stress (Srivastava et al. 2018).

\section{Physiological Characteristics of Distinct Salinity Tolerance in the MDR Landraces}

In general, excess $\mathrm{Na}^{+}$decreases $\mathrm{Ca}^{2+}$ uptake, while supplemental $\mathrm{Ca}^{2+}$ increases $\mathrm{Ca}^{2+}$ concentrations in plants, resulting in improved plant growth under salt stress conditions (Cramer et al. 1991). To precisely evaluate the correlation between accessions tolerant or sensitive to salinity in this study, we analyzed the salinity response of $20 \mathrm{MDI}$ accessions from the Vietnamese Mekong Delta (Figure 3). The salinity response was highly variable among $20 \mathrm{MDI}$ accessions, which can be divided into two distinct groups: a tolerant group of eight accessions (SES score $<4$ ) and a sensitive group of 12 accessions (SES score $>4$ ) (Supplementary Table 4). We also determined mineral concentrations for roots, leaves, and upper stems in these 20 accessions (Supplementary Table 5, Supplementary Figure 1). Concentrations for $\mathrm{Na}^{+}, \mathrm{Ca}^{2+}$, the $\mathrm{Na}^{+} / \mathrm{K}^{+}$ratio, and the $\mathrm{Na}^{+} / \mathrm{Ca}^{2+}$ ratio in the tolerant group were lower than those obtained for the sensitive group (Figure 3A), which was consistent with the results reported by Kumar et al. (2008), except for $\mathrm{Ca}^{2+}$ concentrations, where Kumar et al. (2008) detected higher $\mathrm{Ca}^{2+}$ concentrations in the tolerant group relative to the sensitive group. Moreover, SNP S01_18015212 is located within the mapping interval of three QTLs for salinity tolerance (QTAROqtl-195, QTAROqtl-196, and QTAROqtl-197), which function in $\mathrm{Na}^{+}$uptake, $\mathrm{K}^{+}$concentrations, and the $\mathrm{Na}^{+} / \mathrm{K}^{+}$ratio, respectively (Mansueto et al. 2017).

In roots, $\mathrm{Ca}^{2+}$ accumulates mainly in the cell wall (Demarty et al. 1984) by binding to the cation exchange sites of root cell wall pectin. Plants with low root $\mathrm{Ca}^{2+}$ concentrations thus tend to exhibit low cation exchange capacity (CEC) in their root cell walls (Marschner 2012). Similarly, $\mathrm{Na}^{+}$binds to root cell wall pectin and causes cell wall damage (Byrt et al. 2018). Therefore, crops with low root CEC have been reported to be more tolerant to salinity than those with high root CEC (Bajwa and Bhumbla 1971). The positive correlations observed between SES scores and both $\mathrm{Na}^{+}$and $\mathrm{Ca}^{2+}$ concentrations in roots in this study (Supplementary Figure 1) suggest that root CEC is smaller in the tolerant accessions including Doc Phung. Compared to the salt-sensitive accessions, the salt-tolerant strains of the Mekong Delta population, represented by Doc Phung, may present lower cell wall damage due to lower $\mathrm{Na}^{+}$and $\mathrm{Ca}^{2+}$ binding capacity to cell wall pectin (Byrt et al. 2018; Marschner 2012). Future exploration of the 
association between limited $\mathrm{Na}^{+}$and $\mathrm{Ca}^{2+}$ binding to cell wall pectin and the SNP located in the $3^{\prime}$ UTR of OsPLGG1 will be useful to study the mechanism of salt tolerance in Doc Phung.

\section{Genetic Specificity and Origin of Doc Phung}

Several articles have reported that Doc Phung shows superior salt tolerance, and this study clearly validated the evidence for this promising salt-tolerant accession (Ho et al. 2018; Le 1999; Tin et al. 2021). First, SES evaluation showed that Doc Phung has the highest salt tolerance and the highest values for shoot length ratio, shoot dry weight ratio, and root dry weight ratio, all highly correlated with salt tolerance (Figure 2). GWASs based on these trait indices among the MDI accessions showed that a promising SNP associated with salt tolerance maps to chromosome 1 (Figure 6), in a genomic location distinct from that of the Saltol locus encoding the HKT1;5 transporter, which is associated with salt tolerance in the varieties Nona Bokra and Pokkali (Figure 6). The HKT1,5 genotype at the Saltol locus in Doc Phung was different from the allele harbored by Nona Bokra and Pokkali (Figure 4). Therefore, the origin of salt tolerance in Doc Phung may have originated from accessions cultivated in the Mekong Delta or from the coastal periphery. SNP S01_1801521 in the 3' UTR of OSPLGG1 provides a new option for salinity-tolerant alleles in rice breeding. It is necessary to analyze the relationship between this gene and salt tolerance. This SNP is useful for stacking multiple salinity tolerance alleles in rice breeding.

\section{Conclusion}

We analyzed the relationship between the degree of salt tolerance and physiological characteristics and performed GWASs for the Mekong Delta rice population. We focused on the landrace variety Doc Phung and confirmed it to be particularly resistant to salt exposure (Ho et al. 2018; Le 1999; Tin et al. 2021). The $\mathrm{Na}^{+}$and $\mathrm{Ca}^{2+}$ concentrations in the salt-tolerant accessions allowed us to propose a salinity-tolerant mechanism caused by smaller root CEC. In addition, we identified a gene with a SNP specific to salttolerant accessions obtained from GWASs. This SNP was located in the 3' UTR of OSPLGG1. Overall, our results provide evidence that the salt-tolerant accessions in the Mekong Delta population, such as Doc Phung, have a different Saltol allele from that of Nona Bokra and Pokkali. The causative genomic region of salt tolerance in Doc Phung, which might have been adapted to the Mekong Delta, is a new source for rice salinity tolerance.

\section{Abbreviations}

SES: The standard evaluation system

CEC: Cation exchange capacity

GWAS: Genome-wide association study

OsPLGG1: Chloroplast glycolate/glycerate translocator 1 
HKT1: HIGH-AFFINITY K ${ }^{+}$TRANSPORTER1

IRRI: The International Rice Research Institute

DAT: Days after transfer

DIT: Days into treatment

SNP: Single nucleotide polymorphism

RAD-seq: Restriction site-associated DNA sequencing

GLM: General linear model

PCA: Principal component analysis

LD: Linkage disequilibrium

aa: The amino acid

\section{Declarations}

\section{Ethical Approval and Consent to participate}

This study complied with the ethical standards of Japan, Vietnam, Hokkaido University, and Can Tho University, where this research was conducted.

\section{Consent for publication}

All authors have consented to the publication of this manuscript.

\section{Availability of supporting data}

The RAD-seq data set of the 97-accession MDI has been deposited in the DDBJ database (accession number DRA008414). The data set of the whole-genome resequencing of the $20 \mathrm{MDI}$ accessions has been registered as SUB10778038 into Sequence Read Archive (SRA). The request of availability of the accessions used in this study is asked to TTM (ngttam@ctu.edu.vn).

\section{Competing interests}

The authors declare that they have no competing interests.

\section{Funding}

This study was funded in part by the Can Tho University Improvement Project VN14-P6, supported by a Japanese ODA loan. 


\section{Authors' contributions}

TTN and YKi planned the research. TTN, TW, and YKi designed the research. TTN and YKi prepared rice seed samples. TTN, and TW carried out the experiments. TTN, MSD, SS and TW analyzed the data. DVL, and YKo supervised the materials preparation and data analysis. TTN, TW, MSD, and YKi wrote and improved the manuscript. MSD, TW, YKo, and YKi supervised TTN's PhD study. All authors have read and approved the manuscript.

\section{Acknowledgements}

We gratefully acknowledge Dr. I. Takamure, Dr. N. Saito (Research Faculty of Agriculture, Hokkaido University) and Dr. H. Ky (College of Agriculture, Can Tho University) for their valuable suggestions concerning this study. We thank Mr. TH Phuc, Mr. HN Dien, and Mr. NV Chanh (Mekong Delta Development Research Institute, Can Tho University) for preparing and maintaining rice seeds for this study.

\section{References}

Akbar M, Yabuno T, Nakao S (1972) Breeding for saline-resistant varieties of rice. I. Variability for salt tolerance among rice varieties. Japanese Journal of Breeding 22:8

Anil VS, Krishnamurthy H, Mathew MK (2007) Limiting cytosolic Na+ confers salt tolerance to rice cells in culture: a two-photon microscopy study of SBFI-loaded cells. Physiol Plantarum 129:607-621

Bajwa MS, Bhumbla DR (1971) Relationship between root cationexchange capacity and sodium tolerance of different crops. Plant and Soil 34:7

Barrett JC, Fry B, Maller J, Daly MJ (2005) Haploview: analysis and visualization of LD and haplotype maps. Bioinformatics 21:263-265

Bassil E, Coku A, Blumwald E (2012) Cellular ion homeostasis: emerging roles of intracellular NHX $\mathrm{Na}+/ \mathrm{H}+$ antiporters in plant growth and development. J Exp Bot 63:5727-5740

Batayeva D, Labaco B, Ye C, Li X, Usenbekov B, Rysbekova A, Dyuskalieva G, Vergara G, Reinke R, Leung H (2018) Genome-wide association study of seedling stage salinity tolerance in temperate japonica rice germplasm. BMC Genet 19:2

Bimpong IK, Manneh B, Diop B, Ghislain K, Sow A, Amoah NKA, Gregorio G, Singh RK, Ortiz R, Wopereis M (2014) New quantitative trait loci for enhancing adaptation to salinity in rice from Hasawi, a Saudi landrace into three African cultivars at the reproductive stage. Euphytica 200:45-60

Bonilla P, Dvorak J, Mackill D, Deal K, Gregorio G (2002) RFLP and SSLP mapping of salinity tolerance genes in chromosome 1 of rice (Oryza sativa L.) using recombinant inbred lines. Philipp Agric Sci 85:68- 
Bradbury PJ, Zhang Z, Kroon DE, Casstevens TM, Ramdoss Y, Buckler ES (2007) TASSEL: software for association mapping of complex traits in diverse samples. Bioinformatics 23:2633-2635

Browning BL, Zhou Y, Browning SR (2018) A One-Penny Imputed Genome from Next-Generation Reference Panels. Am J Hum Genet 103:338-348

Byrt CS, Munns R, Burton RA, Gilliham M, Wege S (2018) Root cell wall solutions for crop plants in saline soils. Plant Sci 269:47-55

Cramer GR, Epstein E, Lauchli A (1991) Effects of Sodium, Potassium and Calcium on Salt-Stressed Barley .2. Elemental Analysis. Physiol Plantarum 81:197-202

Davenport R, James RA, Zakrisson-Plogander A, Tester M, Munns R (2005) Control of sodium transport in durum wheat. Plant Physiol 137:807-818

De Leon TB, Linscombe S, Subudhi PK (2016) Molecular Dissection of Seedling Salinity Tolerance in Rice (Oryza sativa L.) Using a High-Density GBS-Based SNP Linkage Map. Rice (N Y) 9:52

De Leon TB, Linscombe S, Subudhi PK (2017) Identification and validation of QTLs for seedling salinity tolerance in introgression lines of a salt tolerant rice landrace 'Pokkali'. PLoS One 12:e0175361

Demarty M, Morvan C, Thellier M (1984) Calcium and the cell wall. Plant Cell and Environment 7:8

DePristo MA, Banks E, Poplin R, Garimella KV, Maguire JR, Hartl C, Philippakis AA, del Angel G, Rivas MA, Hanna M, McKenna A, Fennell TJ, Kernytsky AM, Sivachenko AY, Cibulskis K, Gabriel SB, Altshuler D, Daly MJ (2011) A framework for variation discovery and genotyping using next-generation DNA sequencing data. Nat Genet 43:491-498

Emon RM, Islam MM, Halder J, Fan YY (2015) Genetic diversity and association mapping for salinity tolerance in Bangladeshi rice landraces. Crop J 3:440-444

Faiyue B, Al-Azzawi MJ, Flowers TJ (2012) A new screening technique for salinity resistance in rice (Oryza sativa L.) seedlings using bypass flow. Plant Cell and Environment 35:1099-1108

Ganie SA, Molla KA, Henry RJ, Bhat KV, Mondal TK (2019) Advances in understanding salt tolerance in rice. Theor Appl Genet 132:851-870

Grattan S, Grieve C (1999) Mineral nutrient acquisition and response by plants grown in saline environments. Handbook of plant and crop stress 2:203-229

Gregorio GB, Senadhira D (1993) Genetic-Analysis of Salinity Tolerance in Rice (Oryza-Sativa L). Theoretical and Applied Genetics 86:333-338

Hariadi YC, Nurhayati AY, Soeparjono S, Arif I (2015) Screening six varieties of rice (Oryza sativa) for salinity tolerance. . Procedia Environmental Sciences 28:10 
Ho VT, H. NQ, Pham BC (2018) Evaluating salt tolerance of twenty traditional rice varieties from Vietnam. Tạp chí Khoa học công nghệ và Thực phẩm 14:9

IRRI (2013) SES Standard evaluation system for Rice 5th Edition. p 34

Kader MA, Lindberg S, Seidel T, Golldack D, Yemelyanov V (2007) Sodium sensing induces different changes in free cytosolic calcium concentration and $\mathrm{pH}$ in salt-tolerant and -sensitive rice (Oryza sativa) cultivars. Physiol Plantarum 130:99-111

Kontgis C, Schneider A, Ozdogan M, Kucharik C, Tri VD, Duc NH, Schatz J (2019) Climate change impacts on rice productivity in the Mekong River Delta. Appl Geogr 102:71-83

Krishnamurthy P, Ranathunge K, Nayak S, Schreiber L, Mathew MK (2011) Root apoplastic barriers block $\mathrm{Na}+$ transport to shoots in rice (Oryza sativa L.). J Exp Bot 62:4215-4228

Kumar V, Shriram V, Nikam TD, Jawali N, Shitole MG (2008) Sodium Chloride-Induced Changes in Mineral Nutrients and Proline Accumulation in Indica Rice Cultivars Differing in Salt Tolerance. J Plant Nutr 31:1999-2017

Kumar V, Singh A, Mithra SA, Krishnamurthy S, Parida SK, Jain S, Tiwari KK, Kumar P, Rao AR, Sharma S (2015) Genome-wide association mapping of salinity tolerance in rice (Oryza sativa). DNA research 22:133-145

Kumari S, Sabharwal VP, Kushwaha HR, Sopory SK, Singla-Pareek SL, Pareek A (2009) Transcriptome map for seedling stage specific salinity stress response indicates a specific set of genes as candidate for saline tolerance in Oryza sativa L. Funct Integr Genomics 9:109-123

Le HN (1999) Biodiversity in the Mekong Delta. Community Biodi-versity Development and Conversation Project. Can Tho, Vietnam. Can Tho University

Lee KS, Choi WY, Ko JC, Kim TS, Gregorio GB (2003) Salinity tolerance of japonica and indica rice (Oryza sativa L.) at the seedling stage. Planta 216:1043-1046

Li H, Durbin R (2009) Fast and accurate short read alignment with Burrows-Wheeler transform. Bioinformatics 25:1754-1760

Lutts S, Kinet JM, Bouharmont J (1995) Changes in plant response to $\mathrm{NaCl}$ during development of rice (Oryza sativa $L$ ) varieties differing in salinity resistance. Journal of Experimental Botany 46:1843-1852

Maas EV, Grattan SR (1999) Crop Yields as Affected by Salinity. Agricultural Drainage 38:54

Mansueto L, Fuentes RR, Borja FN, Detras J, Abriol-Santos JM, Chebotarov D, Sanciangco M, Palis K, Copetti D, Poliakov A, Dubchak I, Solovyev V, Wing RA, Hamilton RS, Mauleon R, McNally KL, Alexandrov N 
(2017) Rice SNP-seek database update: new SNPs, indels, and queries. Nucleic Acids Res 45:D1075D1081

Marschner H (2012) Marschner's mineral nutrition of higher plants, 3rd ed. edn. Academic press, Amsterdam; London

Mohammadi-Nejad G, Singh RK, Arzani A, Rezaie AM, Sabouri H, Gregorio GB (2010) Evaluation of salinity tolerance in rice genotypes. Int J Plant Prod 4:199-207

Munns R, Tester M (2008) Mechanisms of salinity tolerance. Annual Review of Plant Biology 59:651-681

Nhung TT, Vo PV, Nghi VV, Bang HQ (2019) Salt intrusion adaptation measures for sustainable agricultural development under climate change effects: A case of Ca Mau Peninsula, Vietnam. Clim Risk Manag 23:88-100

Pawlowicz I, Waskiewicz A, Perlikowski D, Rapacz M, Ratajczak D, Kosmala A (2018) Remodeling of chloroplast proteome under salinity affects salt tolerance of Festuca arundinacea. Photosynth Res 137:475-492

Pick TR, Brautigam A, Schulz MA, Obata T, Fernie AR, Weber AP (2013) PLGG1, a plastidic glycolate glycerate transporter, is required for photorespiration and defines a unique class of metabolite transporters. Proc Natl Acad Sci U S A 110:3185-3190

Platten JD, Egdane JA, Ismail AM (2013) Salinity tolerance, Na+ exclusion and allele mining of HKT1;5 in Oryza sativa and O-glaberrima: many sources, many genes, one mechanism? Bmc Plant Biology 13

Puram VRR, Ontoy J, Linscombe S, Subudhi PK (2017) Genetic Dissection of Seedling Stage Salinity Tolerance in Rice Using Introgression Lines of a Salt Tolerant Landrace Nona Bokra. J Hered 108:658-670

Rahman MA, Bimpong IK, Bizimana JB, Pascual ED, Arceta M, Swamy BPM, Diaw F, Rahman MS, Singh RK (2017) Mapping QTLs using a novel source of salinity tolerance from Hasawi and their interaction with environments in rice. Rice (N Y) 10:47

Rahman MA, Thomson MJ, De Ocampo M, Egdane JA, Salam MA, Shah EAM, Ismail AM (2019) Assessing trait contribution and mapping novel QTL for salinity tolerance using the Bangladeshi rice landrace Capsule. Rice (N Y) 12:63

Ren ZH, Gao JP, Li LG, Cai XL, Huang W, Chao DY, Zhu MZ, Wang ZY, Luan S, Lin HX (2005) A rice quantitative trait locus for salt tolerance encodes a sodium transporter. Nat Genet 37:1141-1146

Rios JJ, Martinez-Ballesta MC, Ruiz JM, Blasco B, Carvajal M (2017) Silicon-mediated Improvement in Plant Salinity Tolerance: The Role of Aquaporins. Front Plant Sci 8:948 
Sakai H, Lee SS, Tanaka T, Numa H, Kim J, Kawahara Y, Wakimoto H, Yang C, Iwamoto M, Abe T, Yamada Y, Muto A, Inokuchi H, Ikemura T, Matsumoto T, Sasaki T, Itoh T (2013) Rice Annotation Project Database (RAP-DB): An Integrative and Interactive Database for Rice Genomics. Plant Cell Physiol 54:E6-+

Shim SH, Lee SK, Lee DW, Brilhaus D, Wu G, Ko S, Lee CH, Weber APM, Jeon JS (2019) Loss of Function of Rice Plastidic Glycolate/Glycerate Translocator 1 Impairs Photorespiration and Plant Growth. Front Plant Sci 10:1726

Singh RK, Kota S, Flowers TJ (2021) Salt tolerance in rice: seedling and reproductive stage QTL mapping come of age. Theoretical and Applied Genetics

Srivastava AK, Lu YM, Zinta G, Lang ZB, Zhu JK (2018) UTR-Dependent Control of Gene Expression in Plants. Trends Plant Sci 23:248-259

Storey JD, Bass AJ, Dabney A, David Robinson D, Warnes G (2004) qvalue: Q-value estimation for false discovery rate control

Sun HX, Li Y, Niu QW, Chua NH (2017) Dehydration stress extends mRNA 3 ' untranslated regions with noncoding RNA functions in Arabidopsis. Genome Res 27:1427-1436

Tam NT, Dwiyanti MS, Koide Y, Nagano AJ, Ky H, Tin HQ, Hien NL, Dung LV, Kishima Y (2019) Profiling SNP and Nucleotide Diversity to Characterize Mekong Delta Rice Landraces in Southeast Asian Populations. Plant Genome 12:1-11

Termaat A, Passioura JB, Munns R (1985) Shoot Turgor Does Not Limit Shoot Growth of Nacl-Affected Wheat and Barley. Plant Physiol 77:869-872

Thomson MJ, de Ocampo M, Egdane J, Rahman MA, Sajise AG, Adorada DL, Tumimbang-Raiz E, Blumwald E, Seraj ZI, Singh RK, Gregorio GB, Ismail AM (2010) Characterizing the Saltol Quantitative Trait Locus for Salinity Tolerance in Rice. Rice 3:148-160

Tian L, Tan L, Liu F, Cai H, Sun C (2011) Identification of quantitative trait loci associated with salt tolerance at seedling stage from Oryza rufipogon. J Genet Genomics 38:593-601

Tin HQ, Loi NH, Bjornstad Å, Kilian B (2021) Participatory selection of CWR-derived salt-tolerant rice lines adapted to the coastal zone of the Mekong Delta. Crop Science 61:277-288

Xie JH, Zapata-Arias FJ, Shen M, Afza R (2000) Salinity tolerant performance and genetic diversity of four rice varieties. Euphytica 116:105-110

Yang W, Wang F, Liu LN, Sui N (2020) Responses of Membranes and the Photosynthetic Apparatus to Salt Stress in Cyanobacteria. Front Plant Sci 11:713

\section{Figures}




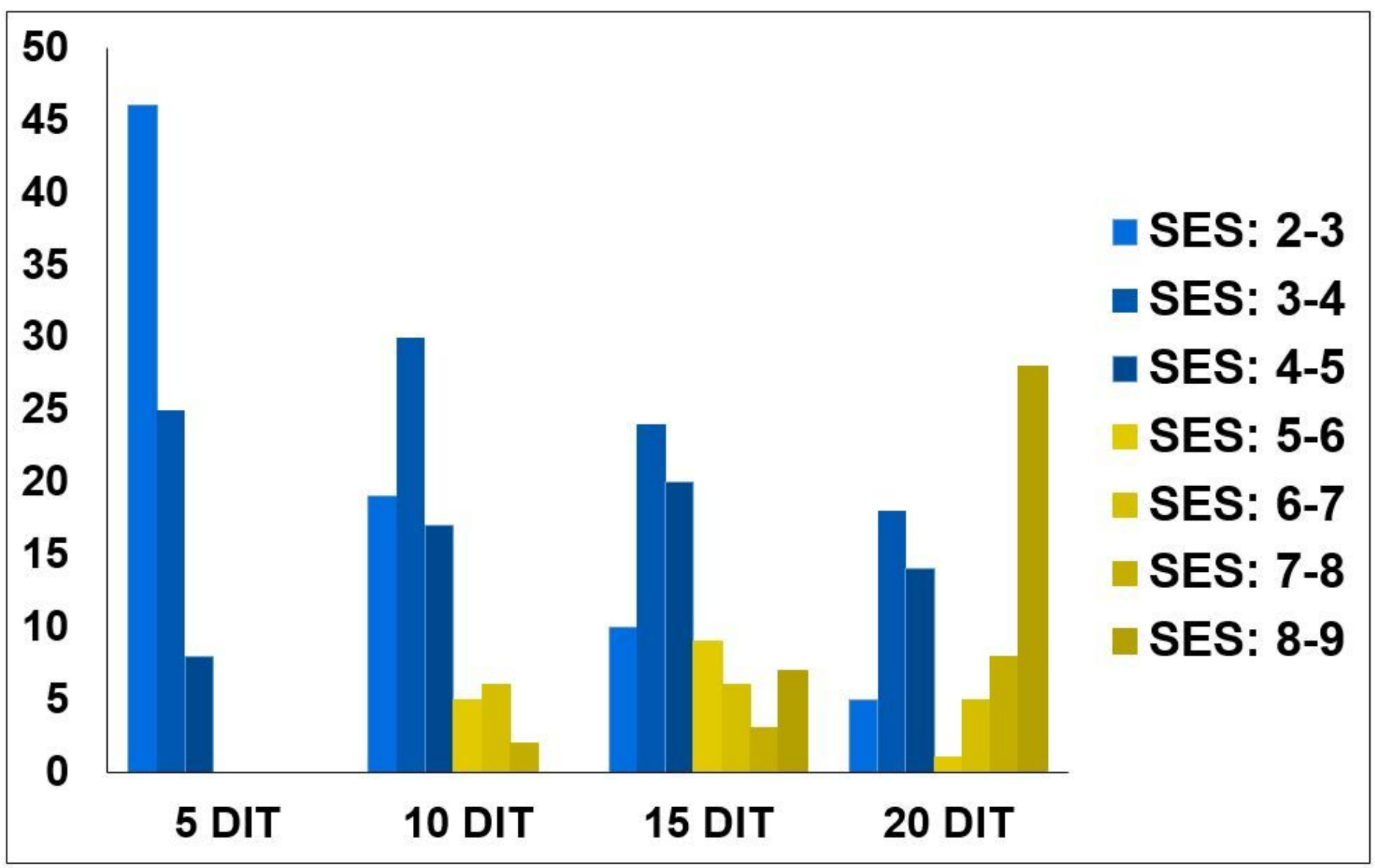

Figure 1

Changes in SES score distributions among 97 accessions from 5 to 20 days into treatment (DIT) with 100 $\mathrm{mM} \mathrm{NaCl}$. The responses of the 97 rice accessions to $100 \mathrm{mM} \mathrm{NaCl}$ treatment were assessed with three replications, evaluated by the SES score, and recorded at 5, 10, 15, and 20 DAT. As indicated in Supplementary Table 2, SES scores were grouped into seven classes: 2-3, 3-4, 4-5, 5-6, 6-7, 7-8, and $8-9$, as indicated by different colors. SES scores of $2-5$ defined salinity-tolerant accessions; SES score above 5 were considered salinity-sensitive accessions. 

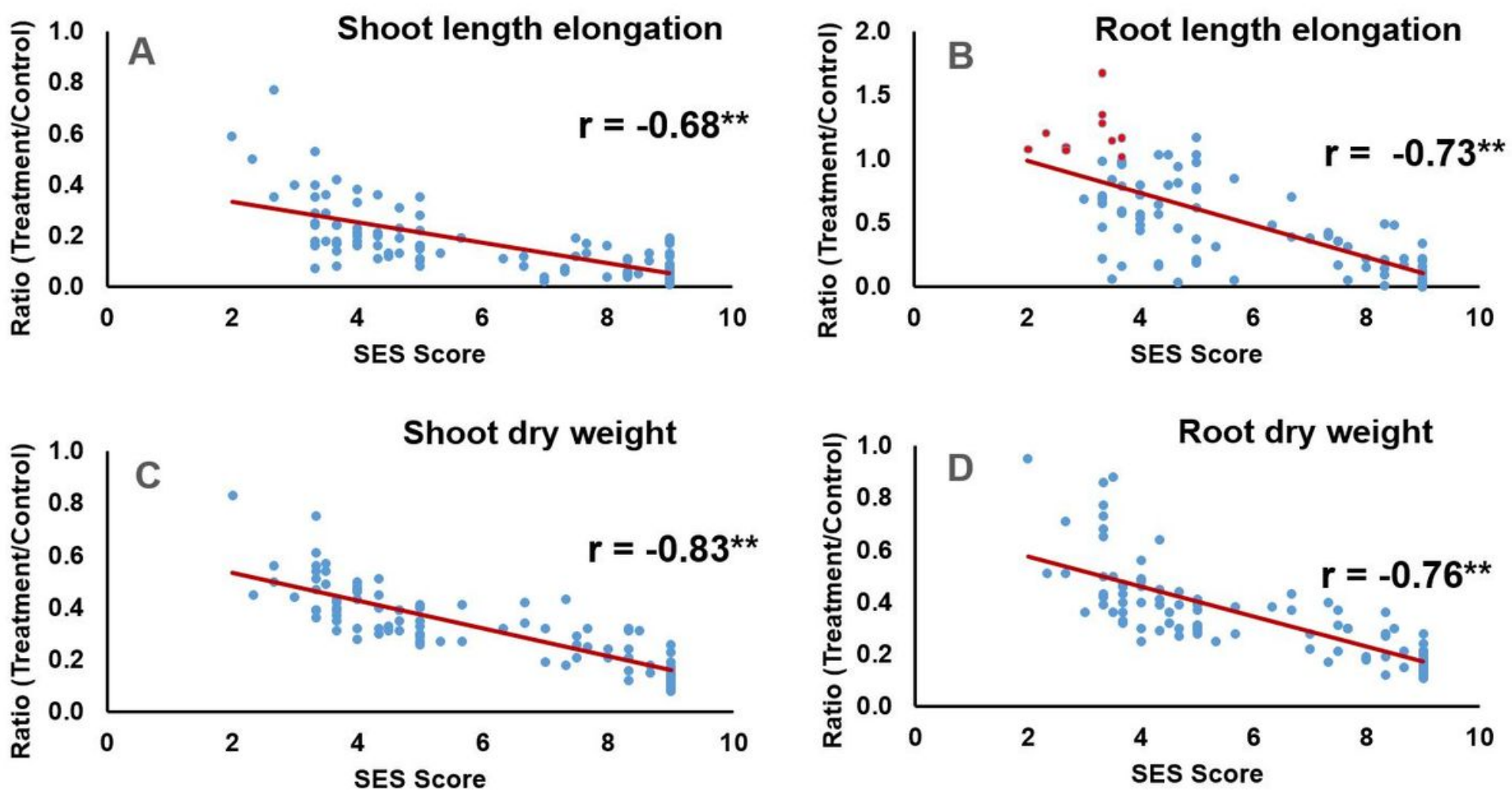

Figure 2

Correlations between four phenotypic traits and SES scores across the 97 accessions at 20 DIT with 100 $\mathrm{mM} \mathrm{NaCl}$. A. Shoot length elongation ratio. B. Root length elongation ratio. C. Shoot dry weight ratio. D. Root dry weight ratio. All correlations were significant ( $p$-value $\leq 0.01$ ). r, Pearson's correlation coefficient.

A

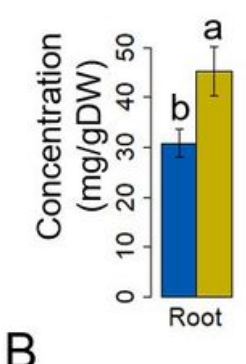

$\mathrm{Na}^{+}$

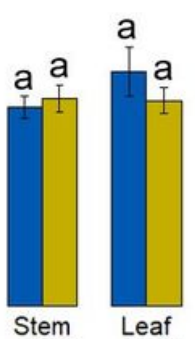

$\mathrm{K}^{+}$

$\mathrm{Ca}^{2+}$

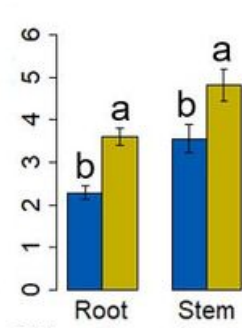

$100 \mathrm{mM} \mathrm{NaCl}$ treatment
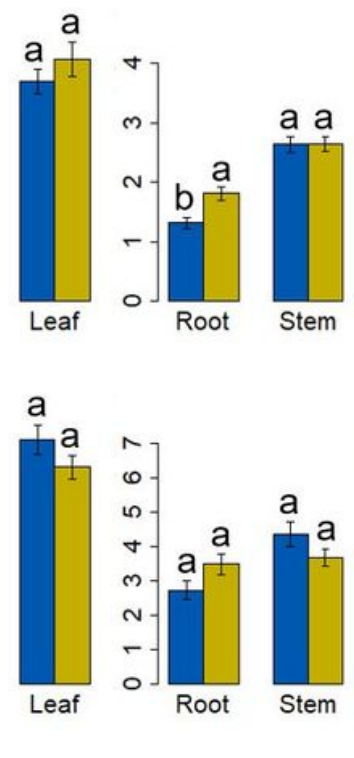

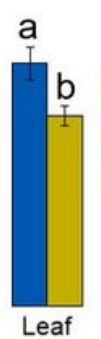

Salinity tolerant group

Salinity sensitive group
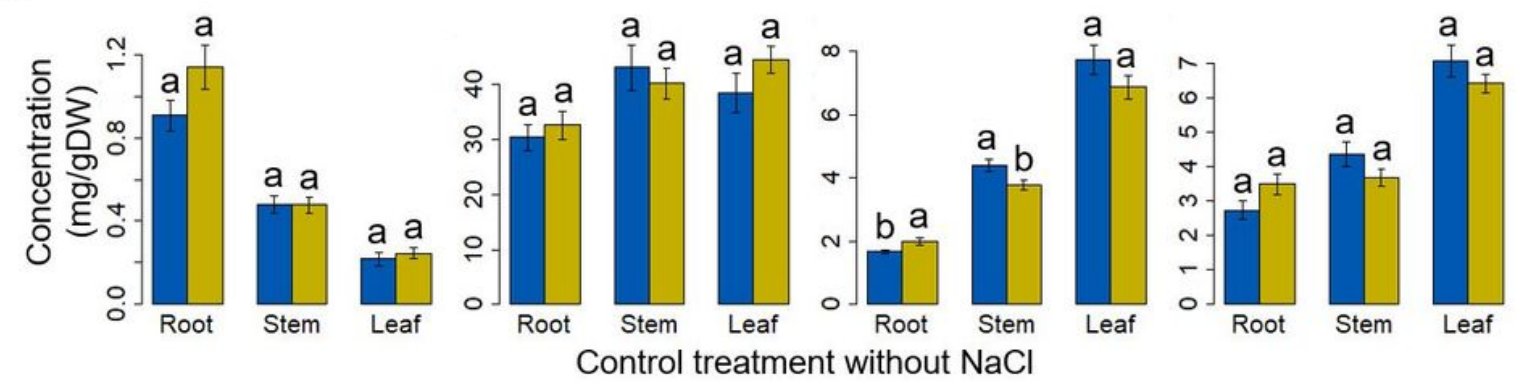

Figure 3 
Concentrations of four mineral ions $(\mathrm{Na}+, \mathrm{K}+, \mathrm{Ca} 2+$, and $\mathrm{Mg} 2+)$ in roots, stems, and leaves for salinitytolerant/sensitive groups. Twenty accessions, consisting of eight tolerant (green: SES scores 2-4) and 12 sensitive (red: SES scores 4-9) accessions, were selected from the initial 97 accessions. A. Accessions treated with $100 \mathrm{mM} \mathrm{NaCl}$ for 20 days (20 DIT). B. Accessions grown under control conditions.

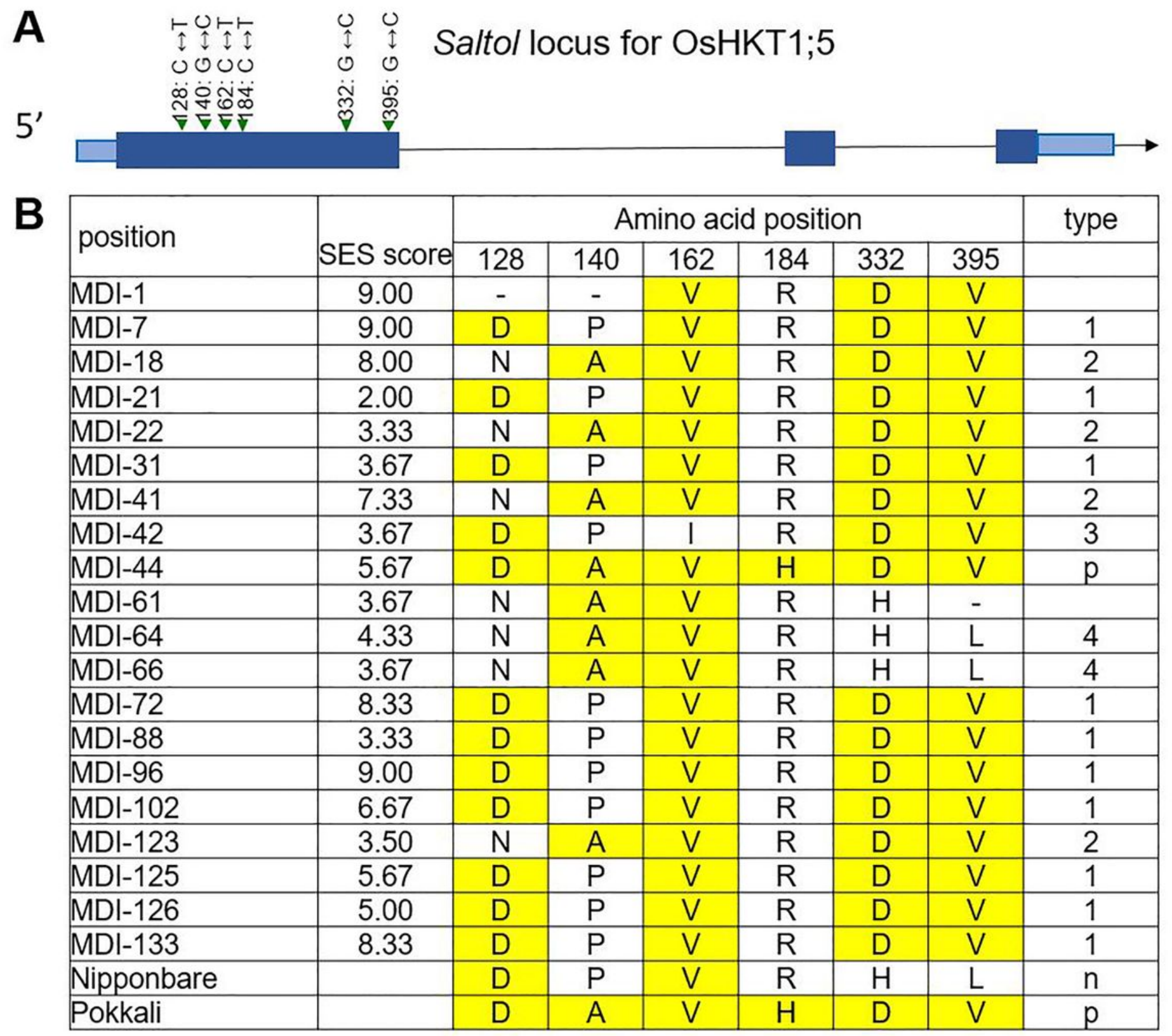

\section{Figure 4}

Comparison of amino acid sequences between $20 \mathrm{MDI}$ accessions and Nona Bokra/Pokkali at OsHKT1;5 encoded by the Saltol locus. A. Schematic diagram of the OsHKT1;5 gene. Dark blue boxes, exons; light blue boxes, untranslated regions; lines, introns. The six positions of $20 \mathrm{MDI}$ accessions indicate the polymorphisms leading to nonsynonymous amino acid (aa) changes relative to the Saltol allele of the Nona Bokra/Pokkali accessions. B. Haplotype analysis of nonsynonymous amino acid substitutions at 
the six sites defined above in each of the $20 \mathrm{MDI}$ accessions. Yellow and (-) represent shared amino acids with Nona Bokra/Pokkali and undetermined amino acids.
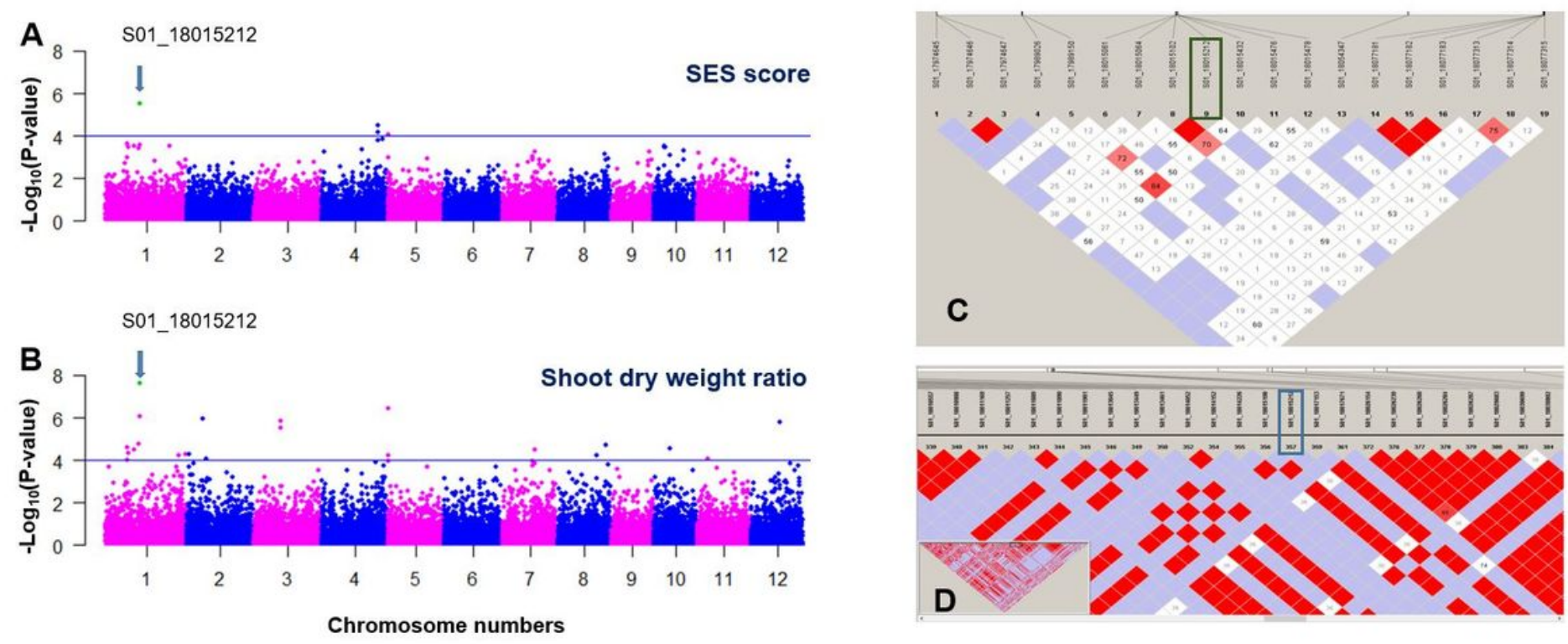

\section{Figure 5}

GWAS of salinity responses with SES scores and shoot dry weights for the MDI accessions. A. Manhattan plot for SES scores with 29,881 imputed SNPs (Tam et al. 2019) from the 79 accessions at 20 DIT with $100 \mathrm{mM} \mathrm{NaCl}$. B. Manhattan plot for shoot dry weight ratio. Both analyses identified a single and identical SNP peak, S01_18015212, on chromosome 1. C. Linkage disequilibrium (LD) analysis showing that S01_18015212 forms a single block using 19 SNPs within $200 \mathrm{~kb}$ obtained by RAD-seq analysis for the 79 accessions. D. LD analysis using 657 SNPs from the 20 accessions, showing a single LD block within the 200-kb window.

Figure 6

A

\section{Chromosome 1}

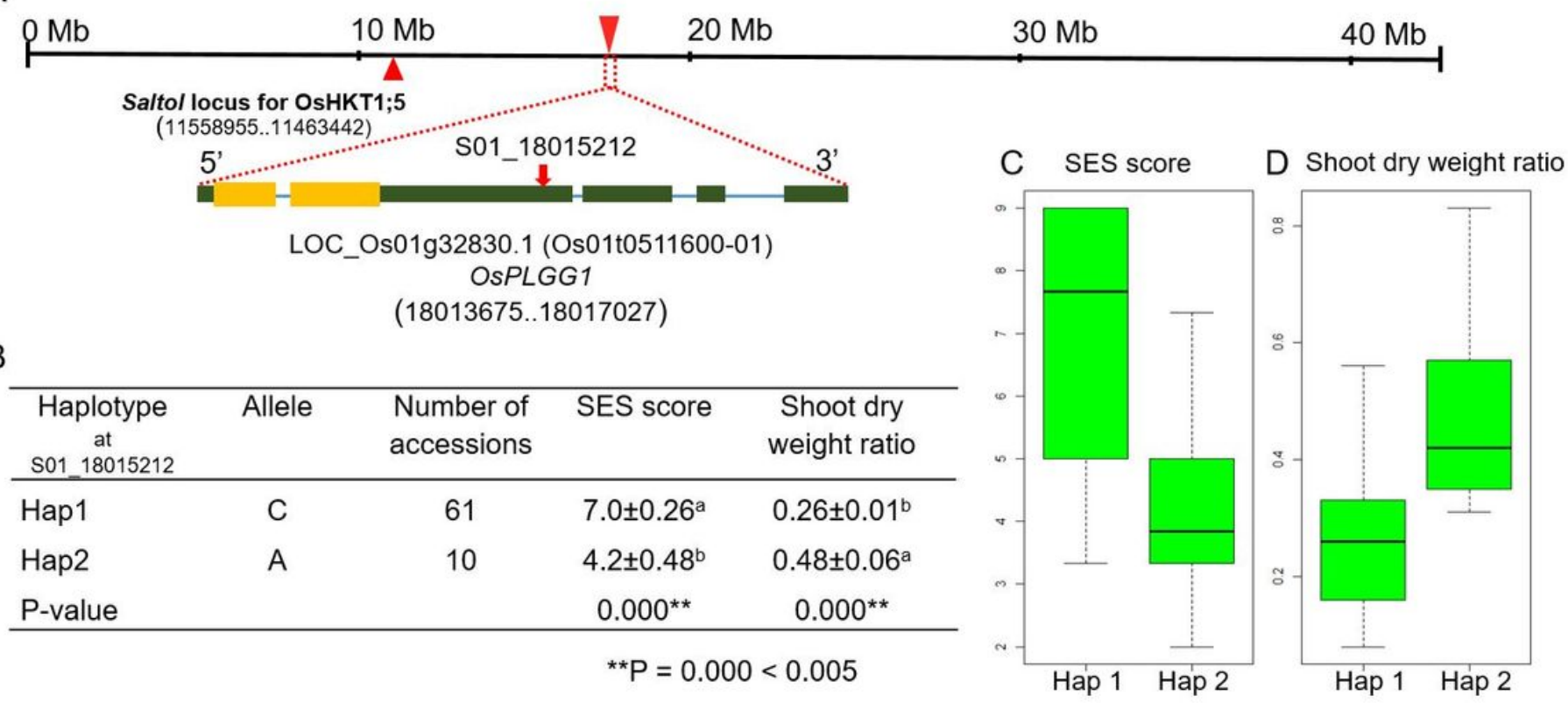




\section{Figure 6}

Location of the SNP peak on chromosome 1 and haplotype analysis. A. Schematic representation of rice chromosome 1 and the position of SNP S01_18015212 within the 3' UTR of LOC_Os01g3283 (OsPLGG1). This gene is $6.5 \mathrm{Mb}$ away from the Saltol locus. B. S01_18015212 defines two haplotypes among 71 accessions: Hap 1 was found in 61 accessions with nucleotide $C$, and Hap 2 was found in 10 accessions with $A$. The remaining eight accessions had no exact haplotype (heterozygous alleles). C, D. Significant differences in SES scores (C) and shoot dry weight ratio (D) values between Hap 1 and Hap 2 accessions.

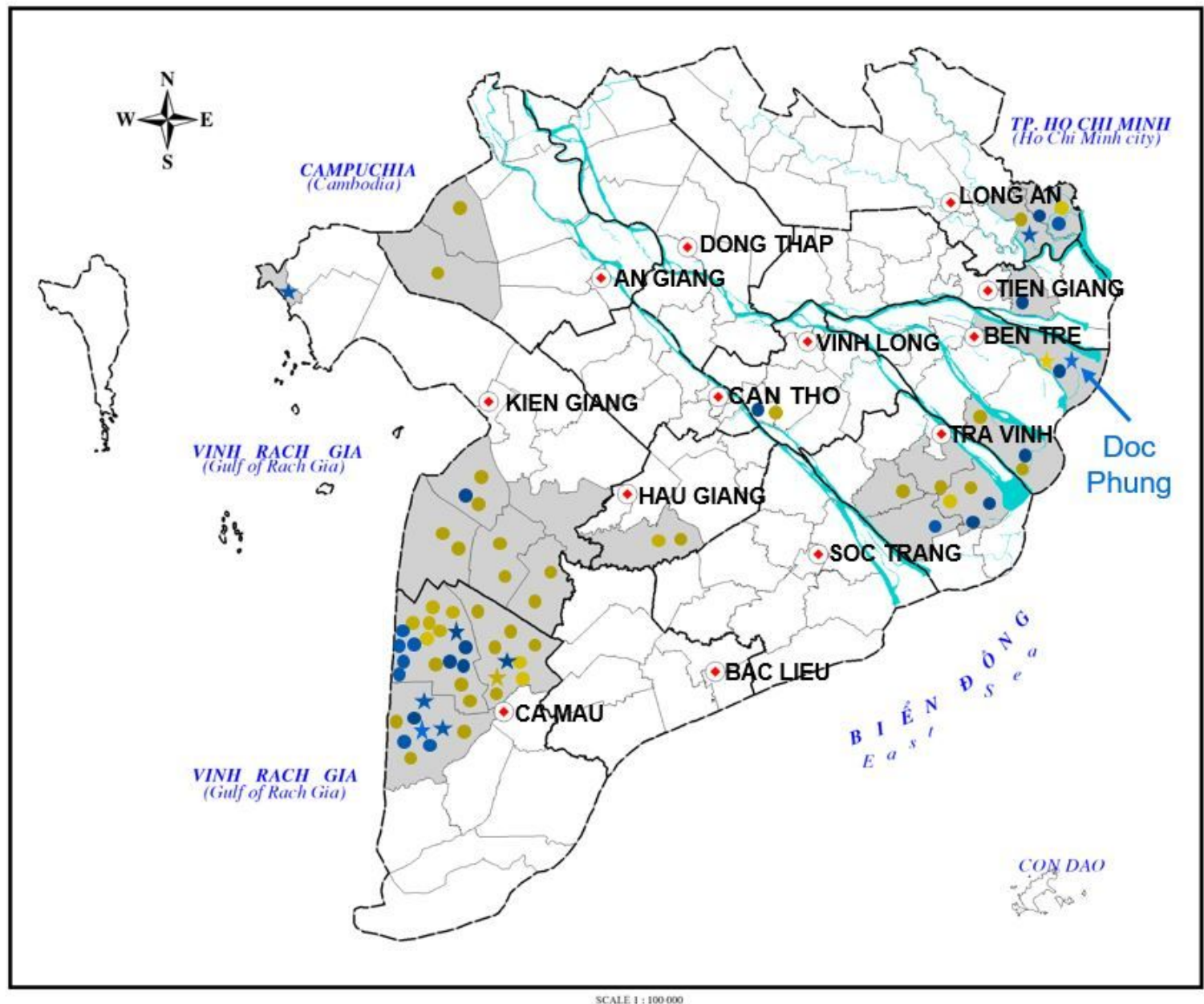

SES: $2-3$

SES: $3-4$

SES: $4-5$

SES: $5-6$

SES: $6-7$

SES: $7-8$

SES: $8-9$

Hap1

Hap2

\section{Figure 7}

Geographical distribution of the $71 \mathrm{MDI}$ landrace accessions in the Mekong Delta as a function of their S01_18015212 haplotype. The map shows the Mekong Delta region in Vietnam. Different colors indicate varying SES scores from Figure 1. The circles and stars indicate Hap 1 (61 accessions) and Hap 2 (10 accessions), respectively.

\section{Supplementary Files}

This is a list of supplementary files associated with this preprint. Click to download. 
- Tametal.SupplementaryFigure1.pptx

- Tametal.SupplementaryTables.xlsx 